\title{
Anxiety and related factors in chronic pain
}

\author{
Gordon JG Asmundson PhD
}

$\mathrm{C}$ linicians often encounter patients who present with both chronic pain and elevated levels of anxiety. In some cases, the source of the anxiety is vague and diffuse. For others, there is an identifiable precipitating object, event or situation. For example, some patients with chronic pain are able to attribute their anxiety to the possibility of not regaining lost functional abilities, financial difficulties, feelings of social inadequacy, or uncertainty about the meaning and consequences of pain. The association between chronic pain and anxiety may not be particularly surprising when one considers that, in the acute phase, both pain and target-oriented anxiety (or fear) motivate actions that serve to minimize the threat and maximize the likelihood of successful escape. As well, their neurobiology, while distinct, interacts in the reticular system (1). Evaluations of the association between chronic pain and fear-relevant constructs were initiated in the 1960s and 1970s $(2,3)$. It has only been of late, however, that theorists and researchers have begun to focus their attention on delineating the precise nature of the relationship and its specific implications for the assessment and management of pain.

What is the nature of this relationship? In discussing a different issue, Merskey (4) articulated several possible explanations. It is possible that one causes the other; that is, fear might cause chronic pain or, alternatively, chronic pain might cause fear. It is also possible that each influences the other. Empirically disentangling and understanding the relationship between chronic pain and fear is a challenging enterprise that is affected by method challenges (eg, sample selection, comorbidity issues, measurement issues). Yet a growing body of evidence suggests that, in the case of chronic musculoskeletal pain and possibly migraine headache, fear is one mechanism through which pain and pain behaviours are maintained over time (reviewed in 5-7).

How does fear act to maintain pain and pain behaviour? Fordyce (8) detailed an operant conditioning model, the essence of which posits that pain behaviours (eg, avoidance, reduced activity) may persist, even after tissue damage has healed, as a consequence of previous successful attempts to escape pain. Others (9-13) have proposed modifications to this operant model - commonly referred to as fear-avoidance models - that incorporate cognitive, behavioural and physiological influences on avoidance behaviour.

Although the specific postulates of the various fearavoidance models differ slightly, the basic premise of each is similar. In essence, if a person has negative expectancies about the harmfulness of pain, they may develop fear of pain or of events and situations that they associate with pain. This fear initiates avoidance behaviour that, over an extended period of time, contributes to deconditioning (eg, muscular atrophy, decreased mobility, weight gain) and, in turn, invigorates further pain experiences, negative expectancies and avoidance. Mounting empirical evidence supports the postulates of the fear-avoidance models and, in doing so, corroborates Waddell's $(14,15)$ position that fear of pain is more disabling than pain itself. This is not to say that organic mechanisms do not play an important role but, rather, that fear may, in many cases, be the mechanism most propitious to understanding the physical performance limitations and disability associated with pain chronicity.

Considerable strides have been made in understanding the role of fear (and anxiety) in chronic musculoskeletal pain and, most recently, in the application of this knowl- 
edge to assessment and treatment issues. The literature on this subject has been comprehensively reviewed and critiqued by Vlaeyen and Linton (7). Still, this area of pain research and management is just in its infancy. There are many unresolved issues. What are the origins of fear of pain, and what mechanisms are responsible for its contribution to the vicious cycle that maintains chronic pain behaviour and disability? Is it unique from other anxiety constructs and trait negative affectivity (ie, depressed mood)? How is it best assessed within clinical and research contexts? Are there effective treatment options for those who have elevated levels of fear of pain?

In answer to some of these questions, Pain Research $\mathbb{E}$ Management has brought together a series of papers, from leaders in the area, that address many of the unanswered theoretical and practice-relevant questions in this area of research. These papers will be presented in a two-part special issue. In the opening paper of Part 1, Turk (pages 9-19) proposes a diathesis-stress model that incorporates a number of the constructs proposed in earlier fear-avoidance models to explain the pathway from traumatic injury to disability. This model should serve as a useful heuristic to researchers and clinicians alike and, if successfully integrated with state-of-the-art knowledge on organic mechanisms, may be of considerable use. The papers of Carter et al (pages 21-30) and Crombez et al (pages 31-39) delve into experimental approaches, respectively applied in the context of induced acute pain and chronic back pain, designed to tease apart the specificity of various emotionality constructs (eg, catastrophizing, depression, trait anxiety) in response to pain. With the contribution of McCracken et al (pages 45-50), the focus shifts to the issue of assessment, specifically the preliminary development and psychometric properties of a short-form of the widely used Pain Anxiety Symptoms Scale (11).

\section{REFERENCES}

1. Panksepp J, Sacks DS, Crepeau LJ, Abbott BB. The psycho- and neuro-biology of fear systems in the brain. In: Denny MR, ed. Fear, Avoidance and Phobias: A Fundamental Analysis. Hillsdale: Erlbaum, 1991:7-59.

2. Spear FH. Pain and psychiatric patients. J Psychosom Res 1967;11:187-93.

3. Merskey H, Boyd D. Emotional adjustment and chronic pain. Pain 1978;5:173-8.

4. Merskey H. Beware somatization. Eur J Pain 2000;4:3-4.

5. Asmundson GJG, Norton PJ, Norton GR. Beyond pain: The role of fear and avoidance in chronicity. Clin Psychol Rev 1999;19:97-119 [reviewed in Clin Res Dig 2001;19:5]

6. Sharp TJ. Chronic pain: A reformulation of the cognitivebehavioural model. Behav Res Ther 2001;39:787-800.

7. Vlaeyen JWS, Linton SJ. Fear-avoidance and its consequences in chronic musculoskeletal pain: A state of the art. Pain 2000;85:317-32.

8. Fordyce WE. Behavioral methods for chronic pain and illness. St Louis: Mosby, 1976.

9. Asmundson GJG. Anxiety sensitivity and chronic pain: Empirical findings, clinical implications, and future directions. In: Taylor S, ed. Anxiety Sensitivity. Mahwah: Lawrence Erlbaum, 1999:269-85.

10. Letham J, Slade PD, Troup JDG, Bentley G. Outline of a fearavoidance model of exaggerated pain perception-I. Behav Res Ther 1983;21:401-8.
In Part 2, to be published later this year, the issue of application in the clinical context takes the forefront. Relevant to assessment and treatment planning, Sullivan et al (16) demonstrate how depression and anxiety contribute to perceived cognitive deficits in people with whiplash injury, and Hadjistavropoulos et al (17) reveal that health anxiety (or worry about having a serious illness) can affect response to cognitive-behavioural treatment approaches. Schmidt et al (18) assess the relationship of pain with anxiety and related constructs from an alternative perspective, looking at pain experiences and impact on cognitive-behavioural treatment in patients diagnosed with panic disorder (an anxiety disorder characterized by unexpected paroxysms of anxiety). Finally, the special issue comes to a close with Vlaeyen et al's (19) comparison of graded activity to exposure in vivo as treatments for fear of pain and pain-associated disability. As a collection, these papers provide empirical insight into some of the outstanding questions and, moreover, provide guidance regarding future directions of the field.

I am grateful to all of the aforementioned authors, not only for their contributions to this two-part issue of Pain Research $\mathcal{E}$ Management, but also for their dedication to their research and practice ventures. My thanks are also extended to the numerous reviewers who provided invaluable critiques of the papers presented herein and to Dr Harold Merskey, Editor-in-Chief of the journal, for his support in dedicating valuable journal space to exploring the state of the art on anxiety and related factors in chronic pain. I hope that the readers of Pain Research $\mathbb{E}$ Management find this series of papers to be helpful in raising awareness and understanding of this emerging body of knowledge and, ultimately, that this translates into improved management strategies and treatment outcomes for patients with chronic pain who are hampered by significant fear and anxiety.

11. McCracken LM, Zayfert C, Gross RT. The Pain Anxiety Symptoms Scale: Development and validation of a scale to measure fear of pain. Pain 1992;50:67-73.

12. Philips H. Avoidance behaviour and its role in sustaining chronic pain. Behav Res Ther 1987;25:273-9.

13. Vlaeyen JWS, Kole-Snijders AMK, Boeren RGB, van Eek H. Fear of movement/(re)injury in chronic low back pain and its relation to behavioral performance. Pain 1995;62:363-72.

14. Waddell G. Keynote address for primary care forum. Low back pain: A twentieth century health care enigma. Spine 1996;21:2820-5.

15. Waddell G. The Back Pain Revolution. Edinburgh: Churchill Livingstone, 1998.

16. Sullivan MJL, Hall E, Bartolacci R, Sullivan ME, Adams H. Perceived cognitive deficits, emotional distress and disability following whiplash injury. Pain Res Manage. (In press)

17. Hadjistavropoulos HD, Asmundson GJG, LaChapelle DL, Quine A. The role of health anxiety among patients with chronic pain in determining response to therapy. Pain Res Manage. (In press)

18. Schmidt NB, Santiago HT, Trakowski JH, Kendren JM. Pain in patients with panic disorder: Relation to symptoms, cognitive characteristics and treatment outcome. Pain Res Manage. (In press)

19. Vlaeyen JWS, de Jong JR, Onghena P, Kerckhoffs-Hanssen M, Kole-Snijders AMJ. Can pain-related fear be reduced? The application of cognitive-behavioural exposure in vivo. Pain Res Manage. (In press) 


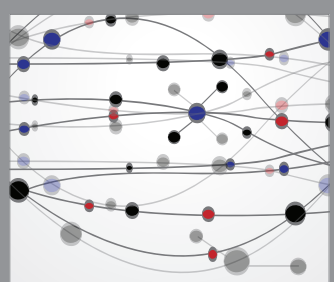

The Scientific World Journal
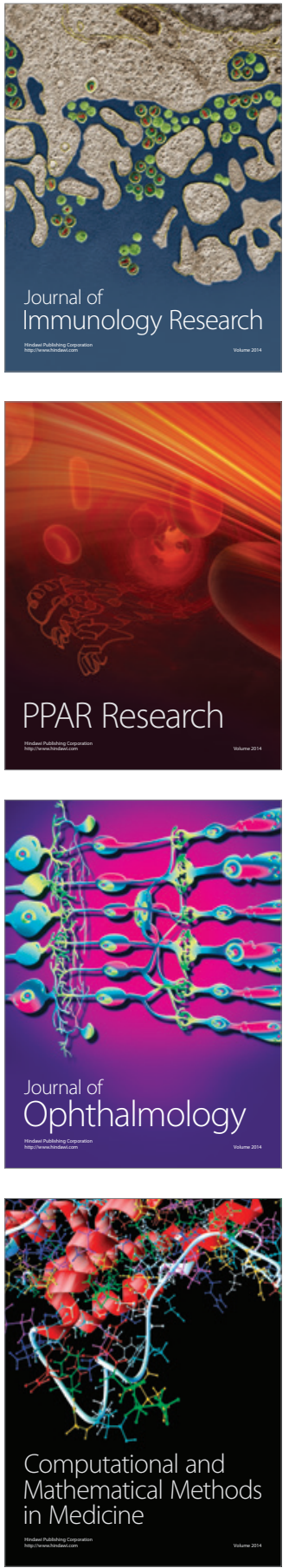

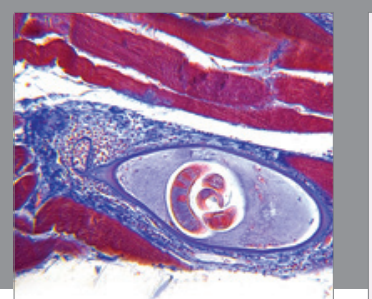

Gastroenterology Research and Practice

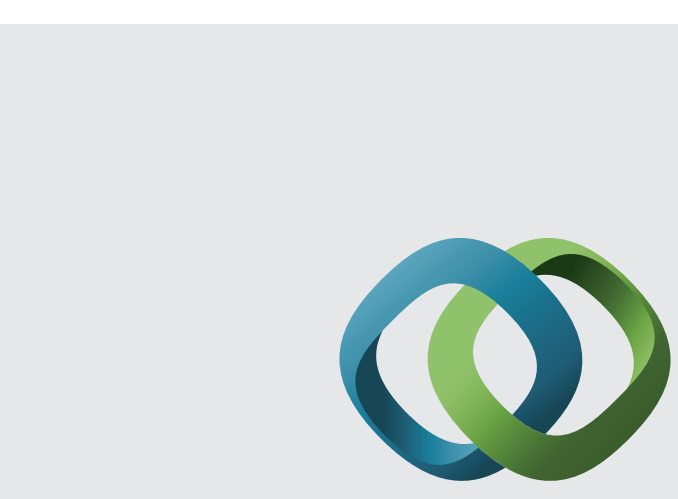

\section{Hindawi}

Submit your manuscripts at

http://www.hindawi.com
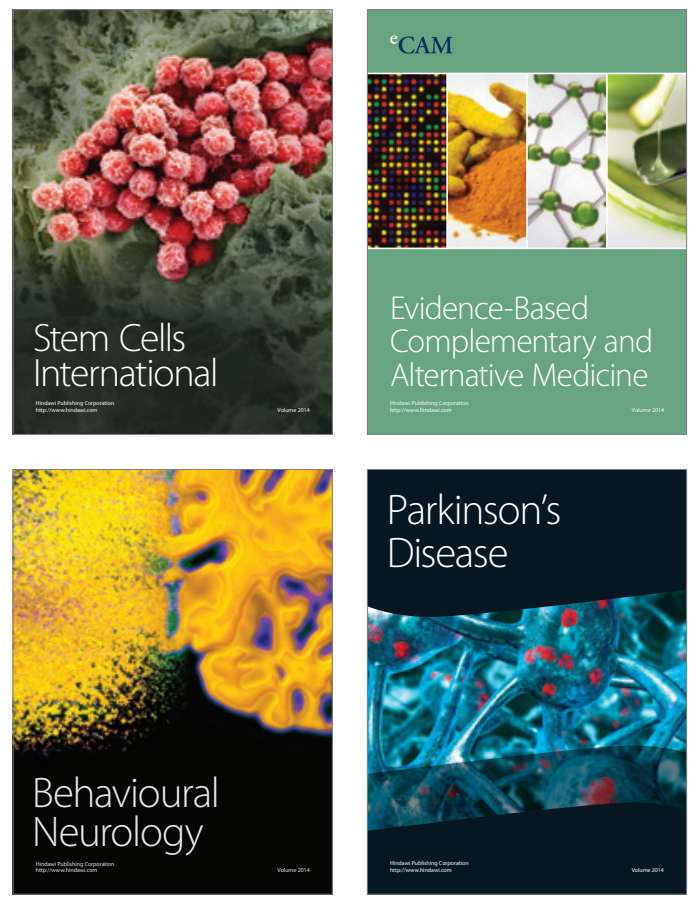
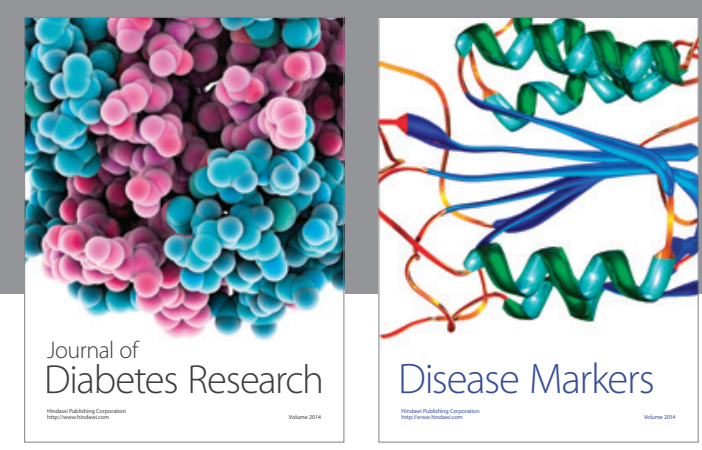

Disease Markers
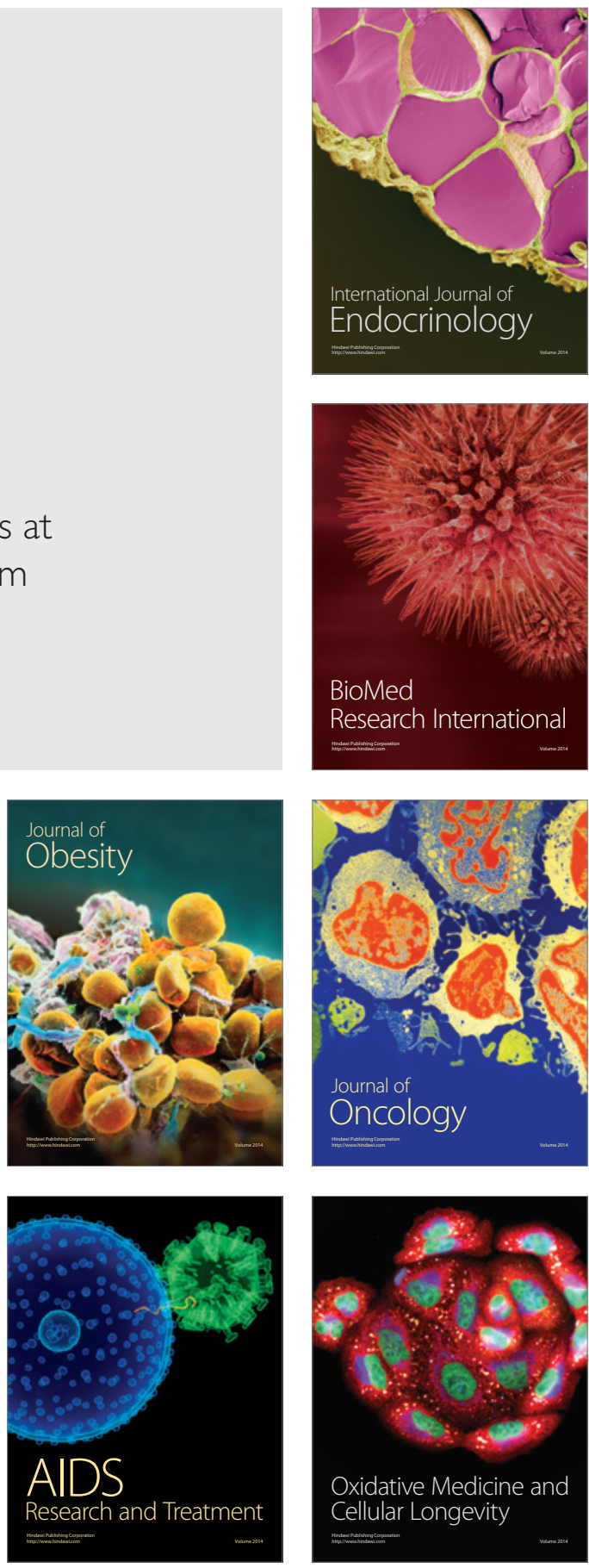